\title{
Characteristics of occult hepatitis B virus infection in the Solomon Islands
}

\author{
TAKAKO UTSUMI $^{1,2}$, YOSHIHIKO YANO ${ }^{2}$, BUI XUAN TRUONG ${ }^{3}$, \\ MASATO KAWABATA ${ }^{2}$ and YOSHITAKE HAYASHI ${ }^{2}$ \\ ${ }^{1}$ Indonesia-Japan Collaborative Research Center for Emerging and Re-emerging Infectious Diseases, \\ Institute of Tropical Disease, Airlangga University, Surabaya 60115, Indonesia; ${ }^{2}$ Center for \\ Infectious Diseases, Kobe University, Graduate School of Medicine, Kobe 650-0017, \\ Japan; ${ }^{3}$ Department of Gastroenterology, Bach Mai Hospital, Hanoi, Vietnam
}

Received January 20, 2011; Accepted February 25, 2011

DOI: $10.3892 / \mathrm{ijmm} .2011 .660$

\begin{abstract}
Hepatitis B virus (HBV) infection is highly endemic in the Solomon Islands. However, little is known about the status of occult HBV infection in the Solomon Islands. This study aimed to investigate the prevalence of occult HBV infection and its clinical and virological features in the community of Solomon Islands. Blood samples were collected from a total of 564 asymptomatic individuals aged over 18 years in the Western province. The samples used in the present study consisted of 200 samples from 108 males and 92 females (mean age, 37.4 years; range, 18-71 years) that were randomly selected among the hepatitis B surface antigen (HBsAg)-negative samples from all the participants enrolled in this study. HBV-DNA was detected by real-time PCR in $25(12.5 \%)$ of the $200 \mathrm{HBsAg-negative} \mathrm{samples.} \mathrm{Most} \mathrm{of} \mathrm{the}$ HBV-DNA-positive individuals were infected with wild-type $\mathrm{HBV}$, and only 3 strains demonstrated specific amino acid substitutions (P121X, T123N, C138S, P142S and D144E) in the $\alpha$ determinant region. In conclusion, occult HBV infection was documented in $12.5 \%$ of individuals that demonstrated serologic evidence of resolved HBV infection in this study. The prevalence of occult infection was also influenced by ethnicity; it was more prevalent in Melanesians than Micronesians. In addition, occult HBV infection demonstrated a weak association with the S-variants.
\end{abstract}

\section{Introduction}

The diagnosis of hepatitis B virus (HBV) infection is usually supported by the detection of hepatitis B surface antigen

Correspondence to: Dr Yoshihiko Yano, Center for Infectious Diseases, Kobe University, Graduate School of Medicine, 7-5-1 Kusunoki-cho, Chuo-ku, Kobe 650-0017, Japan

E-mail: yanoyo@med.kobe-u.ac.jp

Key words: occult hepatitis B virus, community, Solomon Islands
(HBsAg), and the clearance of HBsAg is considered to represent the disappearance of viremia and remission of the disease $(1,2)$. However, occult HBV infection is characterized by the presence of HBV-DNA in HBsAg-negative patients and is associated with more severe liver damage and the development of liver cancer (3-6). Occult HBV infection is often explained by low levels of viral replicative activity and/or mutations in the $\alpha$ epitope of the $S$ gene that encodes amino acid residues 124-147 of HBsAg. Recent epidemiological studies have detected occult HBV infection worldwide (7).

The Solomon Islands are located in the Southwestern Pacific Ocean, and its Western province, which has a multiethnic population, is approximately $380 \mathrm{~km}$ northwest of the capital. Previously, we reported an $\mathrm{HBsAg}$ positivity rate of $21.5 \%$ in a community-based survey of the Western province of the Solomon Islands (8). The aims of this study were to investigate the prevalence of occult HBV infection and its clinical and virological features in the highly endemic country, the Solomon Islands.

\section{Materials and methods}

Sample collection and serological assays. Blood samples were initially collected in September, 2004, from a total of 564 asymptomatic individuals aged over 18 years (mean age, $38.7 \pm 14.6$ years; 281 males and 283 females) in the Western province of the Solomon Islands. All participants signed an informed consent and participated voluntarily in this study in response to an offer of free health examination. The study protocol was reviewed and approved by the Ethics Committee of Kobe University. All 564 serum samples were screened in 2004 for HBsAg by a reverse passive hemagglutination assay (R-PHA) (Mycell II HBsAg; Institute of Immunology Co., Ltd., Tokyo, Japan). A total of 121 samples (21.5\%) were positive for HBsAg. Two hundred samples (mean age, $37.4 \pm 14.2$ years; 108 males and 92 females), were randomly selected among the $443 \mathrm{HBs}$ Ag-negative samples and were used in this study. The prevalence of the antibody against the hepatitis B core antigen (anti-HBc) and of the antibody against the HBsAg (anti-HBs) were assessed by a PHA assay (Mycell II 
Table I. Clinical characteristics of occult HBV infection.

\begin{tabular}{lccc}
\hline Characteristics & Total $\mathrm{n}$ & Occult $(\mathrm{n}=25)$ & Non-occult $(\mathrm{n}=175)$ \\
\hline Gender & & & 98 \\
Male & 108 & $10(9.3 \%)$ & 77 \\
Female & 92 & $15(16.3 \%)$ & 94 \\
Ethnicity & & & 81 \\
Mela & 114 & $20(17.5 \%)^{\mathrm{a}}$ & 1 \\
Micro & 86 & $5(5.8 \%)^{\mathrm{a}}$ & 6 \\
Positive for anti-HBc & 25 & 24 & $38.0 \pm 14.2$ \\
Positive for anti-HBs & 25 & 19 & $17.5 \pm 11.0$ \\
Age (mean \pm SD) & & $33.0 \pm 14.2$ & $4.2 \pm 0.3$ \\
ALT (IU/l) & & $19.1 \pm 9.7$ & $0.5 \pm 0.2$ \\
Albumin (g/dl) & & $4.2 \pm 0.2$ & $0.5 \pm 0.2$ \\
Total bilirubin (mg/dl) & & & \\
\hline
\end{tabular}

Mela, Melanesian ethnicity; Micro, Micronesian ethnicity. ${ }^{a} \mathrm{P}<0.05$.

anti-HBs; Mycell anti-rHBc, Institute of Immunology). The samples were also examined for alanine aminotransferase (ALT), aspartate aminotransferase (AST), albumin, and total bilirubin (T-Bil). Although the prevalence of co-infection with HCV and HIV in our participants is unclear, a previous study reported that the prevalence of anti-HCV was $0.2 \%$ (9). Detailed data of HIV/AIDS is unavailable in the Solomon Islands.

Detection of $H B V D N A$. The sera were stored at $-80^{\circ} \mathrm{C}$ until the assays were carried out. DNA was extracted from $100 \mu 1$ of serum using a DNA extractor kit (Wako Pure Chemical Industries, Ltd., Japan). The presence of HBV DNA was assayed in the surface $(\mathrm{S})$ and pre-core/core promoter $(\mathrm{PC} / \mathrm{CP})$ genes of the viral genome. The $\mathrm{S}$ gene was amplified by PCR with primers $\mathrm{HB} 8 \mathrm{~F}$ and $\mathrm{HB} 6 \mathrm{R}$ for the first PCR, and HB1F and HB1R and/or HB2F and HB2R for the second PCR (10), and the $\mathrm{PC} / \mathrm{CP}$ gene was amplified with primers es2 and $\mathrm{CB} 2$ for the first PCR, and is 2 and CB4 for the second PCR (11). If the results of the $S$ gene PCR were indeterminate, HBV-DNA was detected by single PCR using primers HBSF1 and HBSR1 and/or HBSF2 and HBSR2 (12). The primers HBSF2 and HBSR2 corresponded to a determinant region, which is involved in antigenicity.

Determination of the viral load. The viral load was assessed by real-time PCR using an AB 7500 real-time PCR system (Applied Biosystems, Foster City, CA, USA), which can distinguish between samples containing 5,000-10,000 DNA template copies, with a statistical confidence level of 99.7\%. HBV DNA was amplified with a primer and probe set, as previously described (12).

Confirmation of the HBsAg status in HBV DNA-positive cases. To minimize the possibility of false-negative results for HBsAg and to confirm occult HBV infection, a highly sensitive chemiluminescent immunoassay (CLIA) (Architect, Abbott Laboratories, North Chicago, IL, USA) was used for samples that were HBsAg-negative by R-PHA but HBV DNA-positive by real-time PCR. The sensitivity of the R-PHA for HBsAg (10-12 ng/ml) was less than that of CLIA (0.06-0.08 ng/ml) (13).

Sequence analysis. The amplified fragments were sequenced directly by dideoxy sequencing using the Taq DyeDeoxy Terminator cycle sequencing kit with a 3100-Avant genetic analyzer (Applied Biosystems). The amino acid and nucleotide substitutions (nt 124-147) in S genes were then analyzed.

Phylogenetic analysis. To examine the HBV genotype and sub-genotype, the two $\mathrm{S}$ gene sequences (950 bp) of the strains M37 and P163 found in this study were compared with those of 48 reference sequences retrieved from the DDBJ/ EMBL/GenBank database and with the 4 sequences (M41, P71, R73 and R75) identified in subjects from the Solomon Islands during our previous study (8). The subtypes of the strains used for the comparison were obtained from published articles $(14,15)$. The sequences were aligned using ClustalX software, and phylogenetic trees were constructed by the neighbor-joining (NJ) method (16). To confirm the reliability of the phylogenetic tree analysis, bootstrap re-sampling and re-construction were carried out 1,000 times. The nucleotide distance was estimated with the Tamura-Nei substitution model. These analyses were carried out using the Molecular Evolutionary Genetics Analysis (MEGA) software program (available at http://www.megasoftware.net) (17).

Statistical analysis. Statistical analysis was performed using the $\chi^{2}$ test or the Fisher's exact test for categorical variables. The independent t-test was used for continuous variables, as appropriate. A P-value $<0.05$ was considered to be statistically significant. 
Table II. Characterstics of the individuals with occult HBV infection.

\begin{tabular}{|c|c|c|c|c|c|c|c|c|c|}
\hline ID & Age & Gender & Ethnicity & Anti-HBs & Anti-HBc & $\begin{array}{l}\mathrm{AST} \\
\mathrm{IU} / 1\end{array}$ & $\begin{array}{l}\mathrm{ALT} \\
\mathrm{IU} / 1\end{array}$ & $\mathrm{PC} / \mathrm{CP}$ & S \\
\hline M37 & 64 & $\mathrm{~F}$ & Mela & + & + & 33 & 18 & O & O \\
\hline M76 & 56 & $\mathrm{~F}$ & Mela & + & + & 77 & 10 & & O \\
\hline P103 & 65 & $\mathrm{~F}$ & Mela & + & - & 38 & 18 & & \\
\hline P131 & 22 & $\mathrm{M}$ & Mela & - & + & 24 & 17 & O & \\
\hline P135 & 22 & $\mathrm{M}$ & Mela & + & + & 64 & 29 & & \\
\hline P149 & 29 & $\mathrm{~F}$ & Mela & + & + & 15 & 11 & O & O \\
\hline P152 & 35 & $\mathrm{~F}$ & Mela & + & + & 35 & 31 & & O \\
\hline P155 & 26 & $\mathrm{~F}$ & Mela & + & + & 21 & 16 & O & O \\
\hline P158 & 31 & $\mathrm{~F}$ & Mela & + & + & 34 & 18 & & O \\
\hline P163 & 33 & $\mathrm{~F}$ & Mela & - & + & 23 & 21 & O & O \\
\hline P165 & 64 & $\mathrm{~F}$ & Mela & + & + & 31 & 18 & 0 & O \\
\hline P177 & 32 & $\mathrm{~F}$ & Mela & + & + & 107 & 52 & O & O \\
\hline P181 & 23 & $\mathrm{~F}$ & Mela & + & + & 23 & 22 & & \\
\hline P182 & 19 & $\mathrm{~F}$ & Mela & + & + & 21 & 13 & & \\
\hline P183 & 38 & $\mathrm{~F}$ & Mela & + & + & 37 & 15 & & \\
\hline P184 & 32 & $\mathrm{M}$ & Mela & + & + & 26 & 11 & & \\
\hline P190 & 32 & M & Mela & + & + & 36 & 21 & & O \\
\hline P194 & 34 & M & Mela & + & + & 42 & 34 & 0 & O \\
\hline P209 & 27 & $\mathrm{M}$ & Mela & + & + & 18 & 12 & & \\
\hline R74 & 20 & $\mathrm{M}$ & Micro & - & + & 24 & 28 & & \\
\hline R123 & 18 & M & Micro & + & + & 24 & 11 & & \\
\hline R141 & 22 & $\mathrm{~F}$ & Micro & - & + & 15 & 8 & & \\
\hline R144 & 26 & $\mathrm{~F}$ & Micro & + & + & 30 & 18 & & \\
\hline R148 & 32 & $\mathrm{M}$ & Micro & - & + & 21 & 12 & & \\
\hline R163 & 22 & $\mathrm{M}$ & Mela & - & + & 15 & 13 & & \\
\hline
\end{tabular}

Mela, Melanesian ethnicity; Micro, Micronesian ethnicity; $\bigcirc$, presence of surface $(\mathrm{S})$ or pre-core/core promoter $(\mathrm{PC} / \mathrm{CP})$ genes determined by PCR. HBsAg is negative for all samples. Viral load of all samples is $<2.6 \log$ copies $/ \mathrm{ml}$.

\section{Results}

Prevalence of occult $H B V$ infection. The positivity of anti$\mathrm{HBc}$ and anti-HBs was examined in $200 \mathrm{HBsAg}$-negative samples. HBV-DNA was also assessed using real-time PCR and a conventional PCR assay. In the real-time PCR assay, HBV-DNA was detected in 25 of the 200 individuals (12.5\%), despite their low viral load ( $<2.6 \log$ copies $/ \mathrm{ml})$. Serologically, 24 of the 25 cases $(96 \%)$ were positive for anti-HBc, and 19 of the 25 cases (76\%) were positive for anti-HBs (Table I). In addition, the prevalence of occult HBV infection was significantly higher in Melanesians (17.5\%) than in Micronesians $(5.8 \%)(\mathrm{P}<0.05)$. There was no significant difference in age, the level of ALT, albumin and T-Bil between the occult and non-occult groups. The characteristics of occult HBV infection are listed in Table II. The mean level of HBsAg in the samples confirmed by CLIA was $0.003 \mathrm{IU} / \mathrm{ml}$. Because of limited sample volume, we were unable to examine the level of anti-HBs. Although the quantity of HBV-DNA detected was low, 12 cases demonstrated the presence of fragments of the S and PC/CP genes by conventional PCR analysis. Of these, 8 cases were positive for the $\mathrm{PC} / \mathrm{CP}$ promoter region, and 11 cases were positive for the $\mathrm{S}$ region.

Substitutions in the a determinant region. The HBV S region nucleotide sequences were translated to amino acids and aligned with the reference sequences. As to the putative amino acid analysis of the $\alpha$ determinant region (amino acids 124-147) of the S gene, we found amino acid substitutions as shown in Fig. 1. The specific amino acid substitutions detected in this region were I126, T131 and S143. In addition, strain P158 identified in this study, demonstrated a P143 substitution while strain P190 was shown to have undergone three substitutions: S138, S142 and E144 (Fig. 1).

Phylogenetic analysis. Phylogenetic analysis of the two HBV strains (M37 and P163) found in this study based on the nucleotide sequences of the S gene (nt 18-989) was conducted by comparing their sequences with those of 54 reference consensus sequences retrieved from the DDBJ/ EMBL/GenBank database. As a result, we found that M37 was classified into $\mathrm{HBV} / \mathrm{C} 3$ along with strains from the Solomon 
124

147

\begin{tabular}{|c|c|c|c|c|c|c|c|c|c|c|c|c|c|c|c|c|c|c|c|c|c|c|c|c|c|c|c|c|c|c|c|c|c|}
\hline Al & AF297621 & $120 \mathrm{P}$ & $\mathrm{C}$ & $\mathrm{K} \mathrm{T}$ & C & $\mathrm{T}$ & $\mathrm{T}$ & P & A & $2 \mathrm{G}$ & $\mathrm{N}$ & & $4 \mathrm{~F}$ & $P$ & $\mathrm{~S}$ & $\mathrm{C}$ & $\mathrm{C} \mathrm{C}$ & $\mathrm{C}$ & & $\mathrm{P}$ & & D C & & N C & & $\mathrm{C}$ & I & $P$ & I & $P$ & S S & & 155 \\
\hline $\mathrm{A} 2$ & $\mathrm{~J} 012207$ & 120. & . & . & . & & & . & • & • & & . . & . & . & . & . & . & • & . & 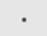 & · & . & . & . & 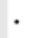 & . & . & . & 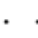 & . & . & & 155 \\
\hline A3 & B194952 & 120. & $\cdot$ & $\mathrm{R}$. & . & • & . . & . . & · & . & . & . . & $\cdot$ & . & - & . & . & · . & · $\cdot$ & . & . & . . & . & $\cdot$ & - & . & . & . & . & $\cdot \cdot$ & . & & 155 \\
\hline B1 & D23678 & 120. & $\cdot$ & $\cdot$ & . & · & . & . & · & . & $\mathrm{T}$ & . . & 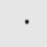 & . & . & . & . & . & · . & . & . & . . & . & . & . & . & . & . & . & · $\cdot$ & . & & 155 \\
\hline B2 & AF 121251 & 120 & $\cdot$ & $\cdot \cdot$ & . & . & . & . & . & . & $\mathrm{T}$ & . . & 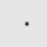 & . & . & . & 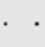 & * & · . & 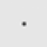 & - & . . & . & 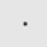 & $\cdot$ & . & . & . & . & . & . & & 155 \\
\hline $\mathrm{C}$ & X75665 & 120 . & $\cdot$ & . . & . & · & I & . & . & . & $\mathrm{T}$ & . . & . & . & . & - & . & . . & . . & . & $\mathrm{S}$ & . . & . & . & . & . & . & - & - & . & . & & 155 \\
\hline D & AJ344117 & 120 & $\cdot$ & $\mathrm{R} \cdot$ & . & M & & $\mathrm{T} \cdot$ & . & . & $\mathrm{T}$ & . . & $\mathrm{Y}$ & . & . & . & & 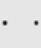 & · $\cdot$ & . & $\mathrm{S}$ & . . & " & $\cdot$ & ${ }^{\circ}$ & . & . & . & . & $\cdot$ & . & & 155 \\
\hline E & X75657 & 120 & $\cdot$ & $\mathrm{R}$. & . & 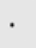 & 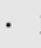 & $\mathrm{L}$. & . & . & $\mathrm{T}$ & . . & . & . & . & . & . & . & S . & . & $\mathrm{S}$ & . . & . & . & . & . & . & . & . & . & . & & 155 \\
\hline $\mathrm{F}$ & $\mathrm{X} 75658$ & 120 & $\cdot$ & $\cdot \cdot$ & . & - & $\cdot$ & $\mathrm{L}$. & . & . & $\mathrm{T}$ & . . & . & - & . & . & . & . & S . & . & $\mathrm{S}$ & . . & . & 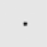 & . & . & . & . & . & . & . & & 155 \\
\hline G & AF160501 & 120 . & . & . . & . & . & . & .. & . & $\cdot$ & · & . . & $\mathrm{Y}$ & . & . & . & . & * & . & . & $\mathrm{S}$ & . . & . & . & . & . & . & . & . & 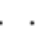 & . & & 155 \\
\hline $\mathrm{H}$ & AY090457 & 120 & $\cdot$ & $\cdot \cdot$ & - & - & 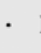 & $\mathrm{L}$. & . & $\cdot$ & $\mathrm{T}$ & . . & 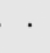 & . & . & . & $\cdot$ & .. & .. & . & $\mathrm{s}$ & . . & . & . & - & . & . & - & • & . & . & & 155 \\
\hline M37 & this study & $120 \cdot$ & $\cdot$ & $\mathrm{R} \cdot$ & . & 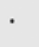 & I & • & $\cdot$ & . & $\mathrm{T}$ & . . & . & ${ }^{\circ}$ & · & . & & - & . & · & $\mathrm{s}$ & $\cdot \cdot$ & . & . & 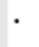 & . & - & . & . & 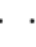 & - & & 155 \\
\hline M76 & this study & $120 \cdot$ & $\cdot$ & $\cdot \cdot$ & - & - & - & . $\cdot$ & · & . & $\mathrm{T}$ & . . & $\cdot$ & $\cdot$ & · & $\cdot$ & - & . . & $\cdot \cdot$ & 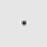 & $\cdot$ & & - & $\cdot$ & $\cdot$ & $\cdot$ & . & - & - & . & . & & 155 \\
\hline P152 & this study & $20 \cdot$ & $\cdot$ & . . & 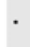 & 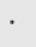 & 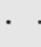 & . & 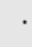 & . & $\mathrm{T}$ & . . & $\theta^{\circ}$ & 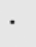 & . & . & 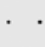 & 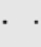 & 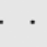 & · & $\mathrm{S}$ & $\cdot \cdot$ & . & . & 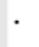 & 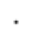 & . & - & 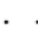 & . & . & & 155 \\
\hline P155 & this study & 120 & · & $\cdot \cdot$ & . & $\cdot$ & I & . . & . & 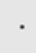 & $\mathrm{T}$ & & . $\cdot$ & - & - & . & & - & $\cdot \cdot$ & - & $\mathrm{S}$ & . . & . & $\cdot$ & $\cdot$ & · & - & - & · & & · & & 155 \\
\hline 158 & this study & 120. & ${ }^{\circ}$ & I $\mathrm{N}$ & & . & . & . & & . & $\mathrm{T}$ & . . & . & . & . & . & 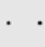 & * & " & . & $\mathrm{P}$ & 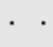 & . & . & . & . & . & . & . & . & . & & 155 \\
\hline P163 & this study & 120 & . & $\cdot \cdot$ & . & $\cdot$ & . & . & & 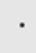 & . & . . & $\cdot$ & . & · & $\cdot$ & & & . & $\cdot$ & $\cdot$ & & & · & $\cdot$ & . & - & . & - & • & - & & 155 \\
\hline P190 & this study & 120 & . & $\cdot \cdot$ & & . & I & . & & $\theta^{\circ}$ & $\mathrm{T}$ & . & . & . & . & . & $\mathrm{s}$. & & . & $\mathrm{S}$ & $\mathrm{S}$ & E . & . & . & . & $\cdot$ & . & . & . & $\cdot \cdot$ & . & & 155 \\
\hline
\end{tabular}

Figure 1. S antigen $\alpha$ determinant amino acid sequence alignment. The first 11 sequences are the consensus sequences of the corresponding HBV genotype/subgenotype reference strains retrieved from the DDBJ/GenBank database. Dots indicate positions with amino acids identical to the HBV/A1 consensus sequence.

Islands and other Pacific regions, and P163 was classified into HBV/A2, which predominates in North West Europe and North America, with a high bootstrap support (Fig. 2).

\section{Discussion}

The disappearance of HBsAg and the appearance of anti-HBs are considered to indicate the remission of hepatic infection. Recently, however, HBV-DNA has been detected in the sera of HBsAg-negative patients, so called occult HBV infection. In the present study, the prevalence of occult HBV infection was high (12.5\%) in the Solomon Islands, a highly endemic region for HBV infection with an HBsAg carrier prevalence of $21.5 \%$. A previous study indicated that the prevalence of occult HBV infection among the general population of China was $2.0-11.5 \%$ (18) and $8.1 \%$ in the Inuit (Eskimo) community (7). Thus, occult HBV infection is common in most regions of the world where HBV infection is endemic.

In the present study, $96 \%$ of the carriers with occult HBV infection were anti-HBc positive, and $76 \%$ were antiHBs positive. Occult HBV infection is more common in individuals that demonstrate serologic evidence of recovery from a previous exposure to HBV (anti-HBc and anti-HBs positive) (4). Twenty-five of 200 individuals that demonstrated anti-HBc and anti-HBs positivity had viral DNA detected in their serum by real-time PCR, even though their viral load was very low. Our results suggest that HBV is able to persist as an occult infection for a long period after the loss of HBsAg, even during the anti-HBs positive phase. Therefore, the serological profile of a patient is not always reliable for determining their HBV infection status, and the clearance of HBsAg followed by the emergence of antibodies does not necessarily indicate the termination of viremia. Occult HBV infection is clinically relevant not only with regard to perinatal transmission of the virus but also in a variety of other settings, including blood transfusion and treatment of patients who are immunocompromised. The most concerning clinical impact of occult HBV infection in the Solomon Islands, however, is the risk of $\mathrm{HBV}$ transmission through the perinatal route from a carrier mother with occult HBV to her child, because blood transfusion or medical practice is uncommon in the Solomon Islands.

Previous studies have suggested that point mutations, deletions, or re-arrangements in several genes of the HBV genome that interfere with gene expression or lead to the production of an antigenically modified S protein may be responsible for the lack of HBsAg during occult infection (19). Accordingly, the amino acid mutations in a determinant region described in this study suggest that they are related to the lack of $\mathrm{HBsAg}$ in occult infection. However, the substitutions (P143, S138, S142 and E144) could possibly exist as variations, since these substitutions have not been described previously. The potential significance of the surface gene mutants for vaccination failure has been studied in several endemic countries (20-22). The Solomon Islands launched a nationwide hepatitis B universal childhood vaccination program in 1977, and the coverage in the Solomon Islands in 2009 was estimated by the World Health Organization/United Nation Children's Fund to be $81 \%$ (Solomon Islands: WHO and UNICEF estimates of national immunization coverage, 1997-2009 (available at http://www.who.int/immunization_monitoring/data/slb.pdf). Because none of the participants of this study were hepatitis B 


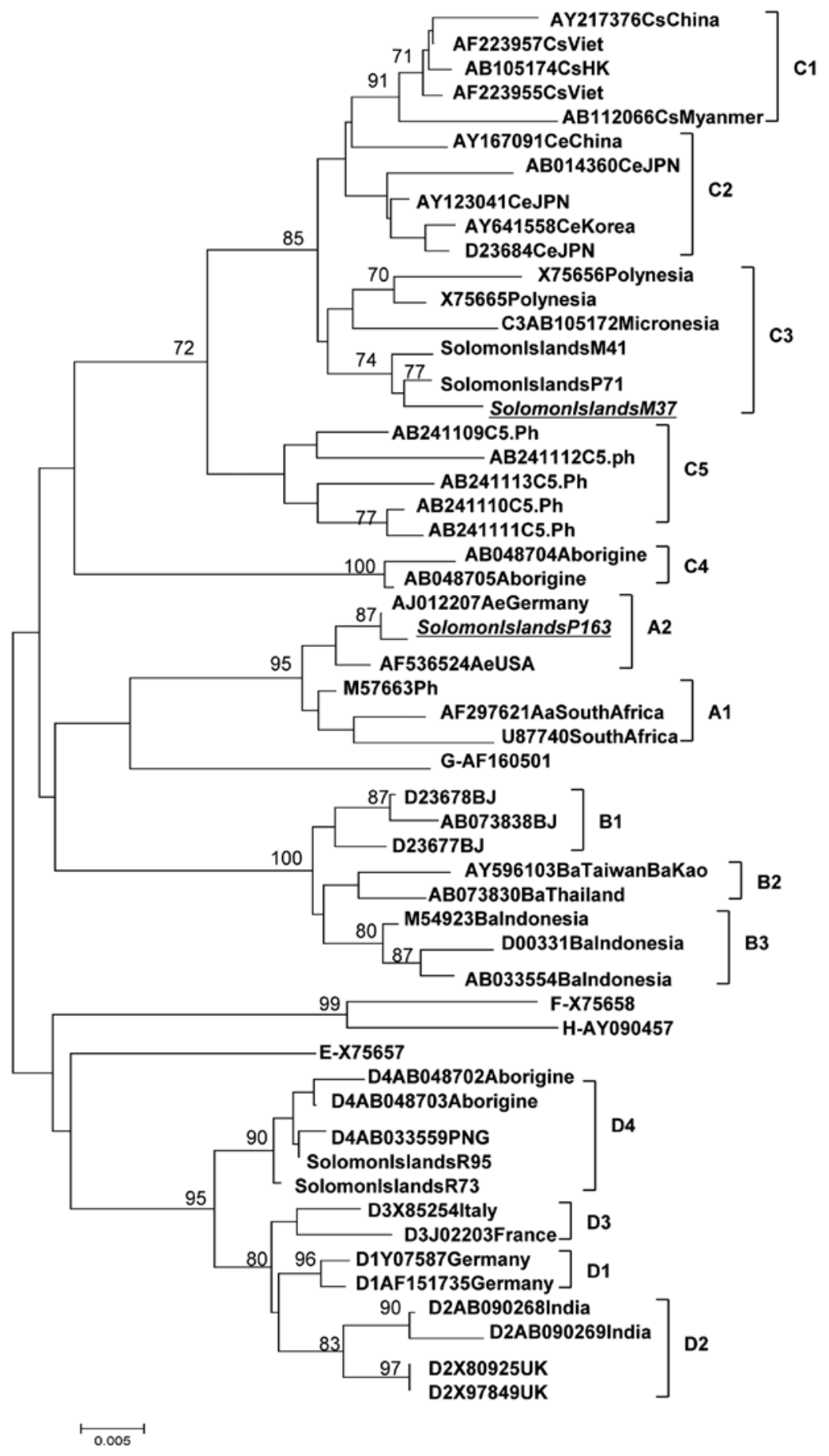

Figure 2. Phylogenetic analysis based on the partial nucleotide sequences of the S genes of two HBV strains (M37 and P163) was conducted by comparing them with those of 54 reference strains. Reference isolates from the database are indicated together with their accession number and the country in which they were found. Bootstrap values (as a percentage of 1000 replicates) are shown at the nodes of the tree. The lengths of the horizontal bars indicate the number of nucleotide substitutions per site.

vaccinated, the relationship between the level of HBV DNA and the vaccination status is uncertain, and the mutations in the $\alpha$ determinant region in this study are impossible to be vaccine escape mutant.

The prevalence of occult HBV infection was higher in Melanesians than in Micronesians, although no difference in HBsAg positivity (8) and the clinical characteristics between the two groups were found. In addition, HBV DNA encoding the PC/CP and HBs regions was only amplified in samples obtained from Melanesians. The HBV genotype C is predominant in Melanesians, as previously reported (8). In this study, we used the set of the primers (SF1 and SR2, SF2 and SR2) in a real-time PCR assay which is frequently used in Japanese HBV isolates in which the predominant genotype is also C. Therefore, Melanesians may be more sensitive to these primers than Micronesians. Furthermore, the 13 samples detected only by real-time PCR and undetected by conventional PCR may have been due to the sensitivity of 
the assay. Susceptibility to infection might also depend on the genotype of the virus, but due to the low HBV viral load, genotypes were only assessed in two individuals. However, little is known about the mechanisms involved in the absence of circulating HBsAg in this ethnic group. Although HBV/A is an uncommon genotype in the Solomon Islands, one of the strains (P163) found in this study was observed to be closely related to a strain from Germany (accession no. AJ012207) due to the low evolutionary distance between them $(0.002$ substitutions per-position). Another strain (M37) was found to belong to $\mathrm{HBV} / \mathrm{C}$, which contains other Solomon Island strains.

In summary, occult HBV infection was documented in $12.5 \%$ of individuals that demonstrated serologic evidence of resolved $\mathrm{HBV}$ infection. The prevalence of occult infection is influenced by ethnicity; the prevalence of infection in Melanesians is higher than that in Micronesians.

\section{Acknowledgements}

This study was supported by a Grant-in-Aid through the Program of Founding Research Centers for Emerging and Reemerging Infectious Diseases from the Ministry of Education, Culture, Sports, Science, and Technology (MEXT), Japan.

\section{References}

1. Gitlin N: Hepatitis B: diagnosis, prevention, and treatment. Clin Chem 43: 1500-1506, 1997.

2. Lee WM: Hepatitis B virus infection. N Engl J Med 337: 1733-1745, 1997.

3. Pollicino T, Squadrito G, Cerenzia G, Cacciola I, Raffa G, Craxi A, Farinati F, Missale G, Smedile A, Tiribelli C, Villa E and Raimondo G: Hepatitis B virus maintains its pro-oncogenic properties in the case of occult HBV infection. Gastroenterology 126: 102-110, 2004.

4. Bréchot C, Thiers V, Kremsdorf D, Nalpas B, Pol S and PaterliniBréchot P: Persistent hepatitis B virus infection in subjects without hepatitis B surface antigen: clinically significant or purely 'occult'? Hepatology 34: 194-206, 2001.

5. Yotsuyanagi H, Shintani Y, Moriya K, Fujie H, Tsutsumi T, Kato T, Nishioka K, Takayama T, Makuuchi M, Iino S, Kimura S and Koike K: Virologic analysis of non-B, non-C hepatocellular carcinoma in Japan: frequent involvement of hepatitis B virus. J Infect Dis 181: 1920-1928, 2000.

6. Cacciola I, Pollicino T, Squadrito G, Cerenzia G, Orlando ME and Raimondo G: Occult hepatitis B virus infection in patients with chronic hepatitis C liver disease. N Engl J Med 341: 22-26, 1999.

7. Minuk GY, Sun DF, Uhanova J, Zhang M, Caouette S, Nicolle LE, Gutkin A, Doucette K, Martin B and Giulivi A: Occult hepatitis B virus infection in a North American community-based population. J Hepatol 42: 480-485, 2005.

8. Utsumi T, Yano Y, Truong BX, Tanaka Y, Mizokami M, Seo Y, Kasuga M, Kawabata M and Hayashi Y: Molecular epidemiological study of hepatitis B virus infection in two different ethnic populations from the Solomon Islands. J Med Virol 79: 229-235, 2007.
9. Furusyo N, Hayashi J, Kakuda K, Sawayama Y, Ariyama I, Eddie R and Kashiwagi S: Markedly high seroprevalence of hepatitis $B$ virus infection in comparison to hepatitis $C$ virus and human $\mathrm{T}$ lymphotropic virus type-1 infections in selected Solomon Islands populations. Am J Trop Med Hyg 79: 85-91, 1999.

10. Sugauchi F, Mizokami M, Orito E, Ohno T, Kato H, Suzuki S, Kimura Y, Ueda R, Butterworth LA and Cooksley WG: A novel variant genotype $C$ of hepatitis $B$ virus identified in isolates from Australian Aborigines: complete genome sequence and phylogenetic relatedness. J Gen Virol 82: 883-892, 2001.

11. Yamamura T, Tanaka E, Matsumoto A, Rokuhara A, Orii K, Yoshizawa K, Miyakawa Y and Kiyosawa K: A case-control study for early prediction of hepatitis B e antigen seroconversion by hepatitis B virus DNA levels and mutations in the precore region and core promoter. J Med Virol 70: 545-552, 2003.

12. Abe A, Inoue K, Tanaka T, Kato J, Kajiyama N, Kawaguchi R, Tanaka S, Yoshiba M and Kohara M: Quantitation of hepatitis B virus genomic DNA by real-time detection PCR. J Clin Microbiol 37: 2899-2903, 1999.

13. Sekiguchi S, Sato S, Kato T and Ikeda H: Effectiveness of a highly sensitive chemiluminescent immunoassay in screening for hepatitis B surface antigen in Japanese blood donors. Transfusion 39: 660-662, 1999.

14. Norder H, Couroucé AM, Coursaget P, Echevarria JM, Lee SD, Mushahwar IK, Robertson BH, Locarnini S and Magnius LO: Genetic diversity of hepatitis B virus strains derived worldwide: genotypes, subgenotypes, and HBsAg subtypes. Intervirology 47: 289-309, 2004

15. Tanaka Y, Orito E, Yuen MF, Mukaide M, Sugauchi F, Ito K, Ozasa A, Sakamoto T, Kurbanov F, Lai CL and Mizokami M: Two subtypes (subgenotypes) of hepatitis B virus genotype C: a novel subtyping assay based on restriction fragment length polymorphism. Hepatol Res 33: 216-224, 2005.

16. Saitou $\mathrm{N}$ and Nei M: The neighbor-joining method: a new method for reconstructing phylogenetic trees. Mol Biol Evol 4: 406-425, 1987.

17. Kumar S, Tamura K and Nei M: MEGA3: integrated software for molecular evolutionary genetics analysis and sequence alignment. Brief Bioinform 5: 150-163, 2004.

18. Fang ZL, Zhuang H, Wang XY, Ge XM and Harrison TJ: Hepatitis B virus genotypes, phylogeny and occult infection in aregion with a high incidence of hepatocellular carcinoma in China. World J Gastroenterol 10: 3264-3268, 2004.

19. Weinberger KM, Bauer T, Böhm S and Jilg W: High genetic variability of the group-specific a-determinant of hepatitis $B$ virus surface antigen ( $\mathrm{HBsAg}$ ) and the corresponding fragment of the viral polymerase in chronic virus carriers lacking detectable HBsAg in serum. J Gen Virol 81: 1165-1174, 2000.

20. Carman WF, Korula J, Wallace L, MacPhee R, Mimms L and Decker R: Fulminant reactivation of hepatitis B due to envelope protein mutant that escaped detection by monoclonal HBsAg ELISA. Lancet 345: 1406-1407, 1995.

21. Lee PI, Chang LY, Lee CY, Huang LM and Chang MH: Detection of hepatitis B surface gene mutation in carrier children with or without immunoprophylaxis at birth. J Infect Dis 176: 427-430, 1997.

22. Tsebe KV, Burnett RJ, Hlungwani NP, Sibara MM, Venter PA and Mphahlele MJ: The first five years of universal hepatitis B vaccination in South Africa: evidence for elimination of $\mathrm{HBsAg}$ carriage in under 5-year-olds. Vaccine 19: 3919-3926, 2001. 